\title{
analysis
}

\section{Thephantom menace}

\author{
Although research may eventually providea cure for hepatitis C, prevention remains thebest strategy \\ against this silent pandemic
}

$\mathrm{H}$ epatitis C is a stealthy and deadly disease. Its causative agent, the hepatitis $\mathrm{C}$ virus ( $\mathrm{HCV}$ ), is transmitted by blood and slowly destroys the liver. Infection becomes chronic in $80 \%$ of cases and leads to cirrhosis, liver cancer, liver failure and eventually death. Hepatitis $C$ is the most prevalent liver disease in the world, the most common cause of liver transplantation in developed countries, and the most frequent blood-borne infection in the USA, where 10,000 people each year die from its complications. There is no vaccine available and current treatments fail in about half of patients. Associated social and healthcare costs on a global scale are incalculable. This is the grim fact sheet of hepatitis $C$, dubbed 'the silent killer' because it may give no sign of its presence for decades, leaving its victims unaware of danger until it is too late for therapy.

According to the World Health O rganization (W H O; Geneva, Switzerland), 170 million people may be chronically infected with HCV worldwide-around 3\% of the world's population-and millions more are newly infected each year (WHO, 2000). But even these figures are not clear. "Recent CDC estimates indicate that the worldwide prevalence of $\mathrm{HCV}$ infection may be closer to $2 \%$, representing approximately 120-130 million persons," said Joseph Perz, an epidemiologist at the Division of Viral Hepatitis of the US Centers for Disease Control and Prevention (CDC; Atlanta, GA, USA). "These estimates are similar to, but lower than, previous WHO estimates, which did not account for the lack of specificity associated with unconfirmed HCV antibody testing or for lower prevalence among younger age groups that are not well represented in surveys." Accurate numbers are lacking particularly for developing countries, where most of the world's population resides, Perz noted, thus global estimates of the prevalence of hepatitis $C$ are difficult to define.

The culprit, HCV, was not discovered until 1989, when M ichael Houghton and his team at Chiron Corporation (Emeryville, CA, USA) isolated a cDNA clone of the viral agent then known to cause post-transfusion 'non-A, non-B hepatitis' (Choo et al, 1989). More than a decade after this discovery, many central questions concerning HCV's life cycle and host interactions remain unsolved, as does the challenge to develop effective therapies and vaccines. Nevertheless, the silent pandemic is finally receiving attention as a major public health problem and recent advances may help scientists to strike the virus at its weak points.

$\mathrm{T}$ reating HCV infection is not a trivial matter. Six basic genotypes of the virus exist, with marked differences in geographic distribution, disease progression and response to therapy. The enveloped RNA virus replicates at an extraordinary pace in vivo and mutates frequently, creating 'escape variants' that baffle the immune system and resist the action of antiviral drugs (Chisari, 2005). Blood transfusions and the re-use of unsterilized needles and syringes are the main means of transmission, whereas sexual and perinatal transmission occurs less frequently. In developed countries, drug abuse with unsterile needles is the predominant source of HCV infection, while unsafe therapeutic injections and transfusions
... many central questions concerning HCV'slife cycle and host interactions remain unsolved, as does the challenge to develop effective therapies and vaccines

remain the main modes of transmission in the developing world (Shepard et al, 2005). $\mathrm{HCV}$ infection is opportunistic in people with human immunodeficiency virus (HIV), with co-infection prevalence rates as high as $90 \%$ among urban injection drug users.

\section{Blood transfusionsand the re-use of unsterilized needles and syringes are the main means of transmission...}

The link betw een HCV and blood transfusion is not new and remains strong. In many developed countries, thousands of recipients of unscreened blood products-mainly haemophiliacs and dialysis patients-were unknowingly infected with HCV during the 1980 s and early 1990s, before testing for the virus became routine. Yet the debate about 'tainted blood' is by no means over, with victims seeking compensation in courts, government officials proposing solutions, and those formerly responsible for blood distribution on trial. Last year, the Canadian Red Cross publicly apologized for having distributed contaminated blood between 1983 and 1990, and the Dutch government faced harsh criticism for not implementing efforts to trace, inform and treat potentially infected people (Laffan, 2005).

A public health problem for rich nations is a plague in poor countries where, owing to financial and organizational constraints, most blood donations are still not screened for HCV, which causes 2.3-4.7 million new infections each year, according to the WHO (Larkin, 2000). The fact that most blood donations in the developing world come from remunerated, non-voluntary donors makes the situation worse, because the prospect of payment encourages potential donors from risk groups to withhold 
important medical information that could preclude donation (Shepard et al, 2005).

A Ithough the scenario may be depressing, scientific progress is more promising. The recent development of a robust in vitro cell-culture system for the virus was one of the biggest advances in $\mathrm{HCV}$ research during the past few years. To dissect the pathogen, researchers have relied for years on a so-called replicon system, based on engineered HCV minigenomes which replicate in transfected human and animal cell lines. Researchers later found that only the replicons with adaptive mutations were able to replicate efficiently in cultured cells. This came at the expense of their ability to infect, as the mutated replicons would not produce new infectious virus particles. Conversely, infectious virus particles produced in vivo failed to replicate in cell culture.

What appeared to be a 'blind alley' suddenly opened up last year when three different groups in the USA and Japan reported that JFH-1, a unique 2a genotype HCV clone isolated from a Japanese patient with fulminant hepatitis, replicated extraordinarily well in cell culture and produced infectious HCV (Lindenbach et al, 2005; Wakita et al, 2005; Zhong et al, 2005). Although it is still not clear what makes JFH-1 so special, researchers in the field hope that it will provide a powerful tool to investigate the mechanisms of virus entry, uncoating, transport, assembly and egress from host cells. This achievement "is already leading to new insights into the viral life cycle and the discovery, testing and development of new antiviral drugs", commented Francis Chisari from the Scripps Research Institute (La Jolla, CA, USA), who leads one of the groups involved in the JFH-1 discovery. "What is needed next is to replicate this breakthrough for other genotypes," remarked Charles Rice, Professor of Virology at Rockefeller University (N ew York, NY, USA), whose team contributed in developing the new infection system. "The next years will see great advances in our understanding of $\mathrm{HCV}$ virus assembly, entry and the functions of the $p 7$ [a small viral integral membrane protein that seems to function as an ion channel] and NS2 [a viral non-structural protein involved in various functions] proteins."

Progress in HCV research has also been hampered by the absence of a suitable small-animal model. Humans and chimpanzees are the only species known to be

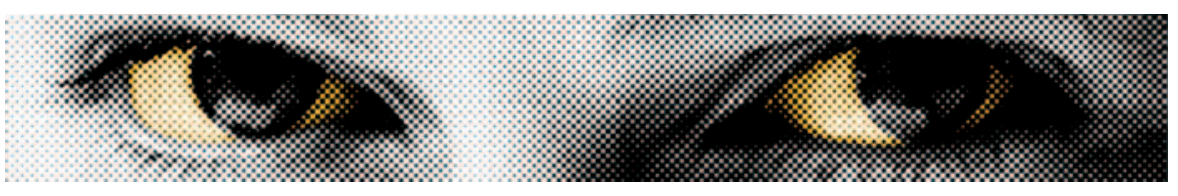

susceptible to HCV, and chimps are expensive and cumbersome to use for in vivo studies. Several teams have therefore adapted a mouse model that carries chimeric human livers to investigate basic HCV biology, an approach pioneered in 2001 by Norman Kneteman and colleagues at the University of Alberta in Edmonton, Canada. Kneteman's group described how the transplantation of normal human hepatocytes into the livers of immunodeficient (SCID -beige) mice carrying a plasminogen activator transgene (Alb-uPA) that is toxic to the mouse hepatocytes, generates animals with nodules of functional human hepatocytes in their livers and capable of surviving while supporting long-term stable infection with HCV (M ercer et al, 2001). Kneteman and colleagues founded a company (KMT Hepatech; Edmonton, AB, Canada) and validated their patented mouse model, KMT Mouse ${ }^{T M}$, by proving that its response to clinically used $\mathrm{HCV}$ agents mirrors that of human patients, so it can be used for predicting the outcome of new HCV-targeted antiviral compounds.

\section{Therecent development of a robust invitrocell-culturesystem for thevirus was one of the biggest advances in $\mathrm{HCV}$ research during the past few years}

"The development of the SCID/Alb-uPA model is a major breakthrough in the study of viral hepatitis," said G eert Leroux-Roels of Ghent University and Ghent Hospital in Belgium, who further characterized the chimeric mice with Philip Meuleman and colleagues (M euleman et al, 2005), "but the model has some drawbacks." For example, "since SCID/Alb-uPA mice are devoid of an immune system, these cannot be used to study the 'host' immune response towards HCV," said Leroux-Roels. "The direct evaluation of new prophylactic or therapeutic vaccines is therefore impossible." D espite these limitations, the researchers believe the SCID/Alb-uPA mouse is the best available alternative to chimpanzees and is useful, among other things, for the in vivo evaluation of potential neutralizing anti-HCV antibodies that could prevent re-infection in chronic HCV patients who receive a liver transplant. Rice agrees that these mice are useful, although problems exist, such as their limited availability. "While they are cheaper than chimps, they are certainly no substitute for the chimp model which mimics many aspects of human HCV infection," commented Rice. "The main use of these mice is for HCV replication studies and the evaluation of antiviral approaches targeting replicative processes, rather than immunomodulatory strategies."

T he development of new anti-HCV drugs is another 'hot front' in the war against the virus. Current standard treatment is based on the combination of interferon and ribavirin, but a substantial number of patients cannot use these medications because of contraindications, or because they simply do not respond to them. Several studies showed that African Americans, people infected with $\mathrm{HCV}$ genotypes 1 and 4, and HIV-HCV co-infected people have significantly lower response rates to combined interferon/ribavirin treatment (Fleckenstein, 2004; Feld \& H oofnagle, 2005). In addition, combination therapy is expensive- which strongly limits its application in developing countries-and causes serious side effects. As the need for better therapies for hepatitis $C$ becomes clearer, more candidate drugs-targeted against virus components or to stimulate the host's immune defences-are entering the development pipeline (Table 1). "The goal for future therapies is that of achieving permanent viral eradication in as many patients as possible," said Raffaele De Francesco of the Istituto di Ricerche di Biologia M olecolare 'P. Angeletti' (Pomezia, Rome, Italy). "Controlling HCV is especially needed in patients after liver transplantation where disease progression is often rapid and conventional treatments are not always feasible," added Markus Reiser, who studies HCV at the Ruhr-U niversität Bochum in Germany.

BILN 2061 (ciluprevir; Boehringer Ingelheim, Laval, Q uebec, Canada) is one such anti-HCV candidate. This small molecule is a potent and specific inhibitor of the HCV NS3 protease, an essential component of the viral replication machine 


\section{saience\& society}

Table1|A selection of anti-hepatitis C drugs and vaccines currently in clinical trials

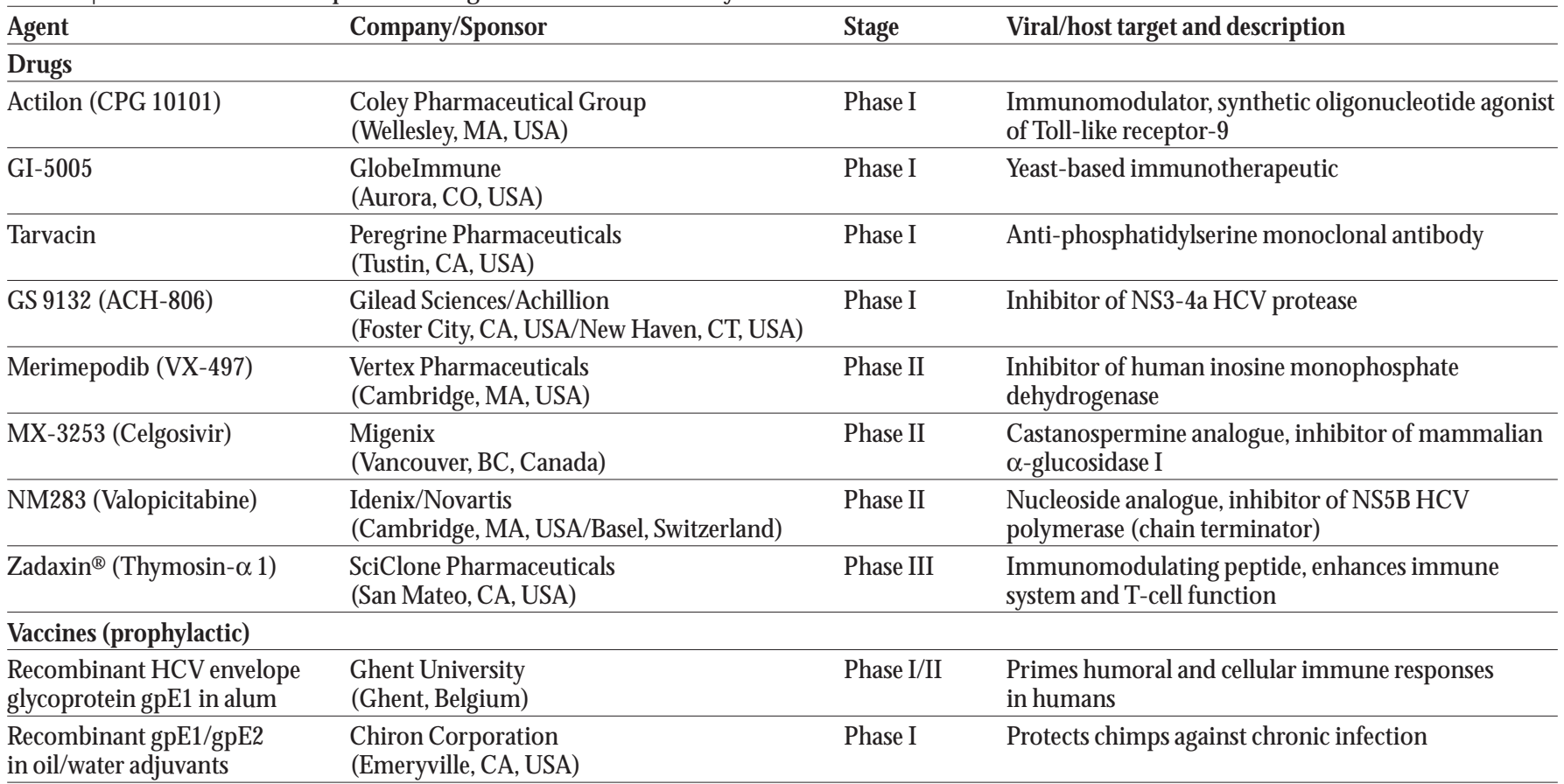

Sources: DeFrancesco \& M igliaccio, 2005; Coley Pharmaceutical Group, www.coleypharma.com; Globel mmune, www.globeimmune.com; PeregrinePharmaceuticals, www.peregrineinc.com; Achillion, www.achillion.com;Vertex Pharmaceuticals, www.vrtx.com; M igenix, www.migenix.com; SciClonePharmaceuticals, www.sciclone.com; H oughton \& Abrignani, 2005.

(De Francesco \& Migliaccio, 2005). Preclinical toxicology data and studies in healthy volunteers proved positive, so the drug entered short-term clinical studies in which it showed impressive results. Oral administration of BILN 2061 for just two days to patients infected with genotype $1 \mathrm{HCV}$ reduced plasma viral RNA levels up to 1,000 fold, raising new hopes and establishing "proof-of-concept in humans for an HCV NS3 protease inhibitor" (Lamarre et al, 2003). However, the BILN 2061 story does not have a happy ending, as animal tests showed that the molecule had serious side effects, specifically cardiac toxicity, which halted the drug's development (Hinrichsen et al 2004; De Francesco \& Migliaccio, 2005). Furthermore, suppression of viral replication was only transient, selection for viruses resistant to NS3 protease inhibitors has already been reported in vitro and in some patients, underlines De Francesco, and not all viral genotypes respond equally well to these agents (Reiser et al, 2005). Notwithstanding these difficulties, Reiser believes that protease inhibitors remain high on the list of future anti-HCV drugs, with their success dependent on the fitness of resistant mutants and on suitable combination partners.

A different $\mathrm{HCV}$ enzyme, namely the RNA polymerase NS5B, is the target of the nucleoside analogue NM283 (valopicitabine), the lead hepatitis $C$ drug candidate of Idenix Pharmaceuticals (Cambridge, MA, USA). Initial clinical trials showed that NM283-co-discovered by Idenix and a group led by Paolo La Colla at the U niversity of Cagliari in Italy - is generally well tolerated and effectively inhibits HCV replication. Phase Il trials are now testing the efficacy of this molecule in combination with interferon on both treatment-naive patients and those who do not respond to standard therapies.

\section{Current standard treatment is based on the combination of interferon and ribavirin, but a substantial number of patients cannot use these medications...}

"The race has thus just started," said De Francesco, "and it is likely that multiple products, acting at different molecular targets, will be developed and combined... to provide the broadest spectrum of action on the different HCV genotypes and to avoid the rapid emergence of inhibitor-repellent viruses." Crucial questions remain, according to De Francesco: what combinations will be most effective in what patients; whether therapeutic regimens based on HCV-targeted drugs will be sufficient to eradicate the infection; and whether patients can be cured without stimulation of the host immune system by either interferons, therapeutic vaccines or other immunomodulatory drugs. And, of course, "safety of new compounds is of utmost importance and resembles a risk in drug development [that is] difficult to preestimate, as seen for BILN 2061 and other, even approved, drugs," said Reiser. "We ... have to await the results of appropriate treatment trials and hope for the best to come."

- or the time being, however, prevention seems to be the best strategy to halt the hepatitis $\mathrm{C}$ epidemic. "Perversely, medical care remains a major mode for HCV infection," said Perz, indicating that safer blood supplies and injection practices would have a positive impact on the incidence of HCV infection in developing countries. "Prevention efforts should also focus on decreasing the number of people who initiate injection drug use, as well as on reducing risks among current injectors through education, drug treatment and other means," he added. N ew public health programmes are also required to identify, counsel and provide medical management for people infected with HCV to reduce the risks for developing chronic liver disease or 
spreading HCV to others. Most importantly, more awareness is needed to bring attention to this silent killer-similar to the attention drawn to HIV in the 1980s-to halt the spread of HCV and to develop therapeutics and vaccines to cure those who are infected.

\section{REFEREN CES}

Chisari FV (2005) Unscrambling hepatitis C virus-host interactions. N ature 436: 930-932

Choo Q L, Kuo G, Weiner AJ, O verby LR, Bradley DW, Houghton M (1989) Isolation of a CDNA clone derived from a blood-borne non- $A$, non-B viral hepatitis genome. Science $\mathbf{2 4 4}$ 359-362

De Francesco R, Migliaccio G (2005) Challenges and successes in developing new therapies for hepatitis C. N ature 436: 953-960

Feld JJ, Hoofnagle JH (2005) M echanism of action of interferon and ribavirin in treatment of hepatitis C. N ature 436: 967-972

Fleckenstein J (2004) Chronic hepatitis C in African Americans and other minority groups. Curr Gastroenterol Rep 6: 66-70

Hinrichsen $\mathrm{H}$ et al (2004) Short-term antiviral efficacy of BILN 2061, a hepatitis C virus serine protease inhibitor, in hepatitis $\mathrm{C}$ genotype 1 patients. Gastroenterology 127: 1347-1355

H oughton M , Abrignani S (2005) Prospects for a vaccine against the hepatitis $C$ virus. N ature 436: $961-966$

Laffan G (2005) Dutch government urged to inform public of blood mistakes. Lancet 365: 2165

Lamarre D et al (2003) An N S3 protease inhibitor with antiviral effects in humans infected with hepatitis $C$ virus. N ature 426: $186-189$

Larkin M (2000) W HO 's blood-safety initiative: a vain effort? Lancet 355: 1245

Lindenbach BD et al (2005) Complete replication of hepatitis $C$ virus in cell culture. Science 309: 623-626

Mercer DF et al (2001) Hepatitis C virus replication in mice with chimeric human livers. $\mathrm{N}$ at M ed 7: 927-933

Meuleman P, Libbrecht L, DeVos R, de Hemptinne B, GevaertK, Vandekerckhove J, RoskamsT, Leroux-Roels G (2005) Morphological and biochemical characterization of a human liver in a UPA-SCID mouse chimera. Hepatology 41: 847-856

Reiser M et al (2005) Antiviral efficacy of N S3serine protease inhibitor BILN -2061 in patients with chronic genotype 2 and 3 hepatitis C. Hepatology 41: 823-835

Shepard CW, Finelli L, Alter MJ (2005) Global epidemiology of hepatitis $C$ virus infection. Lancet Infect D is 5: 558-567

Wakita T et al (2005) Production of infectious hepatitis $\mathrm{C}$ virus in tissue culture from a cloned viral genome. $\mathrm{N}$ at $\mathrm{M}$ ed 11: 791-796

WHO (2000) Hepatitis C. www.who.int/ mediacentre/factsheets/fs164/en

Zhong J, Gastaminza P, Cheng G, Kapadia S, Kato T, Burton DR, W ieland SF, U prichard SL, WakitaT, Chisari FV (2005) Robust hepatitis C virus infection in vitro. Proc N atl Acad Sci USA 102: $9294-9299$

\section{Andrea Rinaldi}

doi:10.1038/sj.embor.7400608

\title{
Gambling in the deep sea
}

\author{
Thegenetic wealth hidden in the deep seas is attracting commercial \\ and academic interest, raising the question whether to regulate \\ bioprospecting in international waters
}

F or decades, the depths of the oceans have fascinated researchers. The discovery of strange creatures perfectly adapted to eternal darkness, high pressure, and other unusual conditions has raised enormous interest in how life emerged on Earth and how it flourishes in such extreme environments (Fig 1). This abundance of life has also lured researchers and biotech companies to the oceans in the hope of finding unknown genes, proteins, and other compounds that could be exploited commercially. Despite the enormous costs that still pose a considerable barrier to deep-sea research and exploitation, some now worry about the negative side effects of deep-sea bioprospecting. Scientists, entrepreneurs, politicians and legal experts have begun to debate problematic issues, such as the preservation of deep-sea biodiversity, habitat protection and sharing of benefits. Their aim is to draft international regulations to prevent environmental and scientific tragedies without hampering discovery.

Scientists have made- and continue to make-exciting discoveries in the depths of the oceans. In the early 1980s, Karl Stetter, a microbiologist from the U niversity of Regensburg, Germany, discovered a hyperthermophilic archaebacterium that flourishes near submarine vents (Fig 2) at temperatures of about $100{ }^{\circ} \mathrm{C}$ (Stetter, 1982). Stetter and his colleagues described another archaebacterium in 2002, termed $N$ anoarchaeum equitans. This organism is parasitic with an unusually small ribosomal RNA and now represents a new phylum in the bacterial world (Waters et al, 2003; Huber et al, 2002).

The first six months of 2005 saw the publication of the discovery of a jellyfish that uses red fluorescent flashes to lure fish (Haddock et al, 2005) and the genome sequence of Photobacterium profundum strain SS9 (Vezzi et al, 2005), 20 years after the microorganism was isolated from an amphipod animal living 2,500 $\mathrm{m}$ deep in the Philippine Sulu Sea (Yayanos, 1995).
Tim Shank, a biologist at Woods Hole O ceanographic Institution (WHOI; Woods Hole, MA, USA), is studying a worm that lives at $80^{\circ} \mathrm{C}$ in an oily tar-like pit near submarine vents. The organism lives in the presence of carcinogenic amounts of polyaromatic hydrocarbons, but does not develop cancer. According to Shank, studying the DNA-repair mechanisms of the organism may lead to new insights about cancer growth and even possible treatments.

S hank's research is just one example of the potential commercial possibilities emerging from the genetic wealth in the deep sea, sometimes coined 'blue gold'. U ntil now, only a few products have made it from research to market. Diversa (San Diego, CA, USA) and New England Biolabs (NEB; Ipswich, M A, USA) sell DNA polymerases isolated from deep-sea vents that offer advantages such as increased thermostability and improved proofreading capabilities for the polymerase chain reaction. Sederma (Le Perray en Yvelines, France) sells Venuceane ${ }^{\mathrm{TM}}$, a skin protection product that includes a radicalscavenging enzyme originally discovered in extremophile bacteria from the Gulf of California (Lintner et al, 2002). However, the global sales of marine biotechnology products in 2002, including anti-cancer compounds, antibiotics and antivirals, were estimated at about US $\$ 2.4$ billion (BCC, 2003).

Such a healthy market for products encourages companies and academics to explore the oceans further for interesting organisms. Diversa, which produces enzymes, proteins and biologically active compounds for pharmaceutical, agricultural and industrial use, maintains an active deep-sea research programme, although it is not the focus of their research, according to Leif Christoffersen, Biodiversity Product Manager at Diversa.

However, the lines between academia and industry are becoming increasingly 